\title{
Enhanced Dipole Antenna for RFID by Using Metamaterials
}

\author{
Nail Alaoui ${ }^{*}$, Aicha Djalab ${ }^{2}$, Lakhdar Bouhamla $^{1}$, Abdellah Azouze $^{3}$, Rania Ibtissam Benmelouka ${ }^{4}$, Sara Daoudi $^{5}$ \\ ${ }^{1}$ Laboratoire de Recherche Modélisation, Simulation et Optimisation des Systèmes Complexes Réels, Université ZIANE Achour \\ de Djelfa, Ain Chih, Djelfa 17000, Algeria \\ ${ }^{2}$ Department of Electrical Engineering, Faculty of Technology, University of Djelfa, P. O. B. 3117, Djelfa, Algeria \\ ${ }^{3}$ Advanced Electronic Systems (LSEA), Electrical Engineering Department, Faculty of Technology, MEDEA University, \\ Algeria \\ ${ }^{4}$ Laboratoire d'Electronique de Puissance et Commande Industrielle (LEPCI), Dept. of Electronics, University of Ferhat Abbas, \\ Sétif -1-, Sétif 19000, Algeria \\ ${ }^{5}$ RCAM Laboratory Dept. of Electronics, Djillali Liabès University, Sidi Bel Abbes 22000, Algeria
}

Corresponding Author Email: n.alaoui@univ-djelfa.dz

https://doi.org/10.18280/rces.080204

Received: 22 April 2021

Accepted: 12 June 2021

\section{Keywords:}

RFID antenna, microstrip dipole antenna, metamaterials antennas, split ring resonators, wireless technology, UHF range

\begin{abstract}
The paper at hand discusses a novel method of miniaturization of antenna design using metamaterials. We suggest a novel method to improve frequency characteristics while reducing antenna size. This method is based on the connection of this element resonant two split rings resonator. The resonant frequency, return loss, bandwidth, radiation pattern, gain, directivity, electromagnetic field, and current supplied by the proposed antenna are the parameters addressed in this study. CST software generates all simulation results.
\end{abstract}

\section{INTRODUCTION}

Metamaterials are artificial material which have unique natural features [1-4]. Metamaterials Their electromagnetic characteristics theoretically proposed by Veselago in 1968 [1] typically attract considerable attention in the scientific community.

In 1999, Pendry empirically confirmed these characteristics [2]. One year later, Shelby et al. [3] were approving the existence of a material by left hand to demonstrate experimentally the existence of two periodic, homogeneous split-ring resonators which can produce a negative efficient permeability and metal files, which produce negative effective permittivity and therefore achieve refractive efficiency. Some years later, Sanada et al. [4] suggested a technique to use a transmission line based on a microstrip technology to create metamaterials left hand. Some researchers have quickly developed miniature methods and improved performance antennas that usually react to RFID technology [5]. The methods of fractal pattern and folding dipole are among the most common. Another method to use [6-11] to increase metamaterial characteristics. In this backdrop, we suggest a novel approach to the development of this essential RFID tag technology working in the UHF band in this article.

The first component is to depict our metamaterial antenna construction suggested by the combination of two traditional divided ring resonators with a dipole antenna on the microstrip. In the second phase, an examination of the findings determines the advantage gained from this structure.

The rest of the paper is as follows: Section 2 briefly describes RFID technology; Section 3 gives an overview of antenna structure; Section 4 presents the results and comparison; and finally conclusions are given in section 5 .

\section{RFID TECHNOLOGY}

Radio Frequency Identification is a wireless technique designed to increase traceability and is currently carried out via the barcode. The RFID system consists of a base station to read the information in the product's chip. The chip and antenna are referred to as RFID tag. In order that RFID tags, be successful in that market, they must always have the best frequency and compact size qualities to be placed in all goods. For the use of various technologies many frequency bands were assigned. The UHF antennas of $2.45 \mathrm{GHz}$ are at the focus of this paper.

\section{METHODS}

The antenna structure of the suggested metamaterials is of the circular dipole form provided by a discrete port with a horizontal excitation and a resistance $\mathrm{R}$ equal to $50 \mathrm{ohms}$. The antenna is positioned between two divided hexagonal split ring resonators, as the Figure 1 below illustrates.

These 3 units have a dielectric substrate with a ROGERS RO4232 type informed by the permittivity of a relative $\mathrm{Er}=3.2$ permeability and a loss of tangent $\tan =0.0018$ (conts.fit). The substrate consists of a cubic geometric form with a height of $\mathrm{h}=1.6 \mathrm{~mm}$ and a side of $100 \mathrm{~mm}$.

The first split ring resonator (exterior part) is hexagonal split with outer ring radius its $39 \mathrm{~mm}$ « $\mathrm{R} 1 »$ and its opening gap «D» equivalent to $4 \mathrm{~mm}$ and its $« \mathrm{~W} »$ track wide of $1.5 \mathrm{~mm}$ outside the structure.

The second split-ring resonator (inner part) is a hexagonal construction with an inner ring radius «R2» of $29 \mathrm{~mm}$ from the ring and a gap "D" of $4 \mathrm{~mm}$ with a gauge of "W" of $1.5 \mathrm{~mm}$. 
There is a circular dipole antenna between these two resonators with a horizontal shape.

The dipole antenna being examined is defined by its diameter, equivalent to « $\mathrm{R}_{\text {antenna" }} 34 \mathrm{~mm}$, partly below half the wavelength $\lambda$. It also has a track of $1.5 \mathrm{~mm}$ width "W.", as the following picture shows, the goal is to ensure the continuity of the distribution current inside the structure.

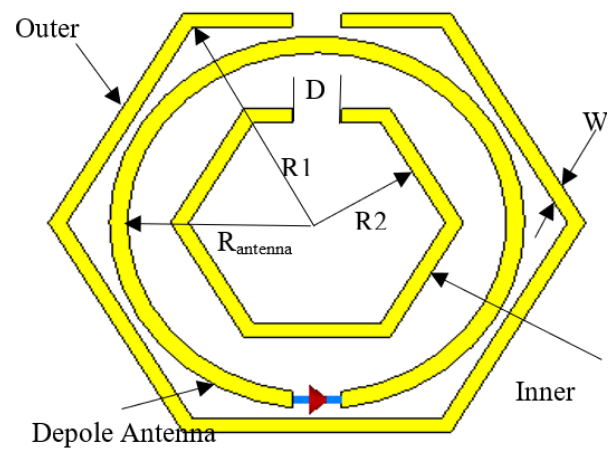

Figure 1. Metamaterials geometric parameters of antennas

\section{RESULTS AND DISCUSSION}

The findings indicate that this structural antenna has extremely low resonance peak of about $2.45 \mathrm{GHz}$, as seen in the curve of the retour loss in Figure 2. The findings seem to be somewhat conflicting when metamaterials are included. This combination enables us to enhance the antenna and make it more flexible to an approximate $2.4 \mathrm{GHz}$ resonance frequency with a return loss $\mathrm{S} 11$ equivalent $-22.7 \mathrm{~dB}$ with a ' $\mathrm{Bf}$ frequency range equal to $180 \mathrm{MHz}$ the decrease of the frequency of resonance by $50 \mathrm{MHz}$ is the result of metamaterial presence. The Figure 3 show that.

Therefore, we get a second Resonance peak according to this structure, which is lower than the primary antenna resonant frequency. With this new frequency of operation, a considerable decrease in the size of the antenna.

The metamaterial and its above geometry exhibit a gain of $2.46 \mathrm{~dB}$ and a directivity equal to $2.52 \mathrm{dBi}$ the Figures 4 and 5 show that.

If we get a " $\eta$ " efficiency of $97 \%$ from Eq. (1) for the efficiency antenna in accordance with the gain and radiation pattern.

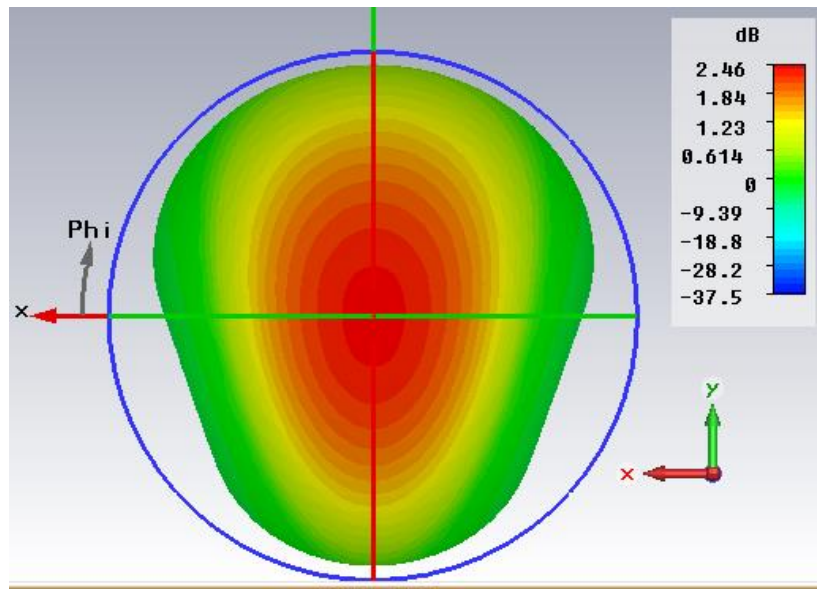

Figure 4. The Metamaterials antenna radiation pattern for the gain calculation

$$
\eta=\frac{\text { Gain }}{\text { Direcivity }} \times 100
$$

By utilizing metamaterials, this novel approach for attending improvement allows us to enhance the antenna's electromagnetic surfaces.

The antenna in presence of the metamaterials has thus been established, shown in Figures 6, 7, with a maximum electropanel of $24717 \mathrm{~V} / \mathrm{m}$ and a maximum magnetic surface area of $74.9 \mathrm{~A} / \mathrm{m}$. The antenna is shown in Figures 6,7 . In the absence of any metamaterials, the rate of progression is $16008 \mathrm{~V} / \mathrm{m}$ and $44.1 \mathrm{~A} / \mathrm{m}$ as opposed to the dipole antenna.

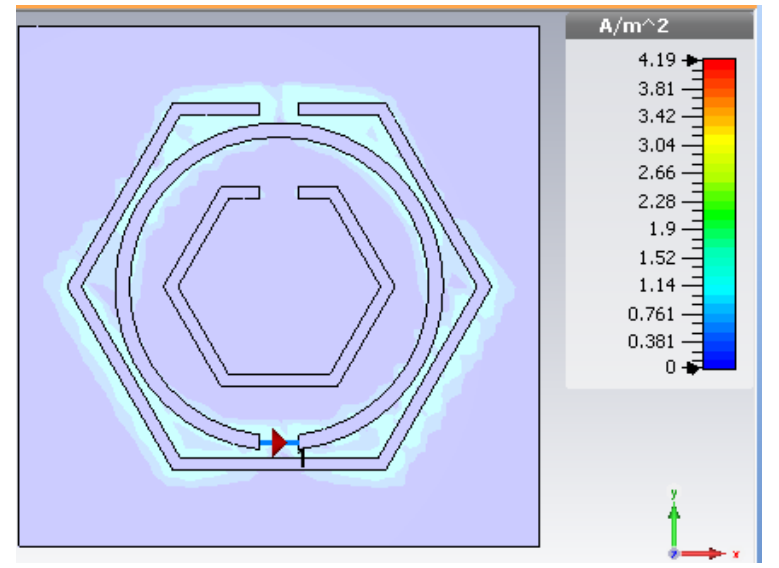

Figure 2. Current circulation of the antenna metamaterials

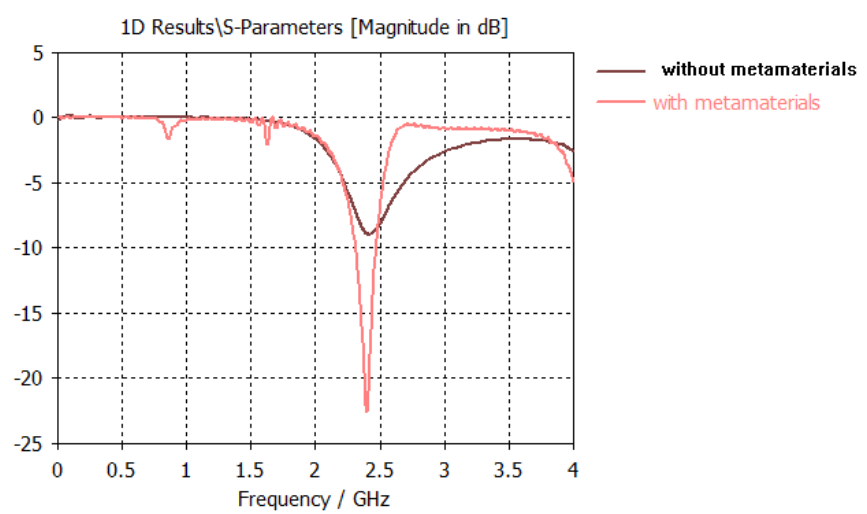

Figure 3. Measure the antenna-typical return loss

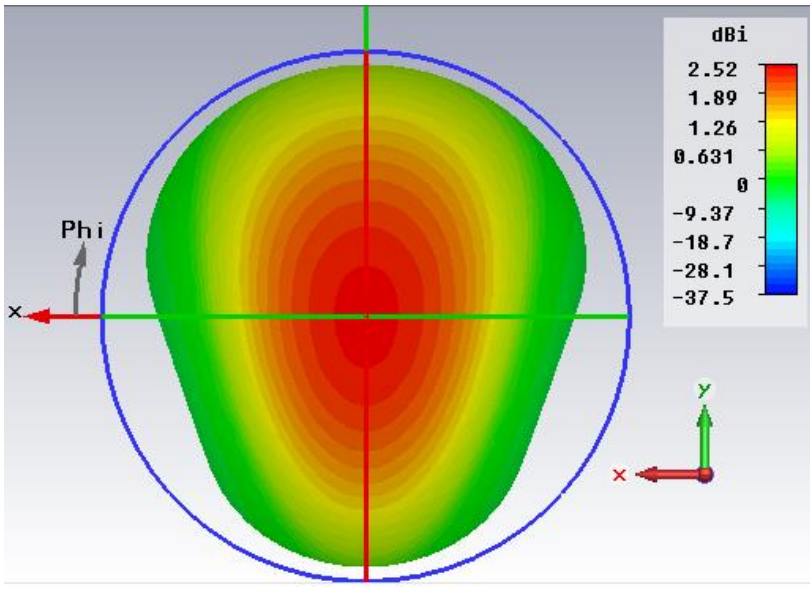

Figure 5. Metamaterials antenna radiation pattern for the calculation of guidance 


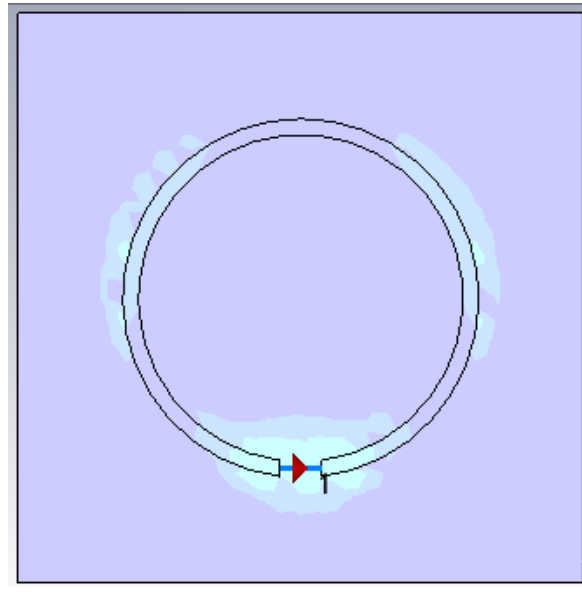

(a) Antenna with metamaterials without metamaterials

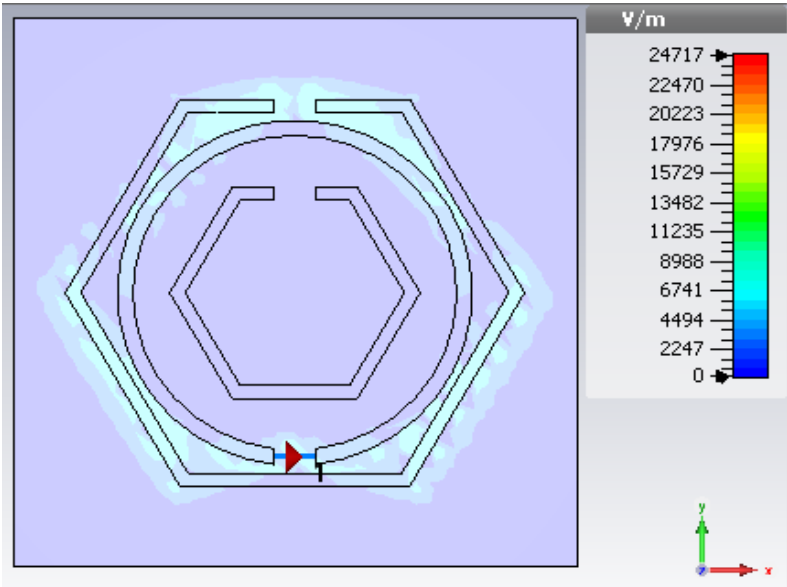

(b) Metamaterial antenna

Figure 6. Electric field distribution

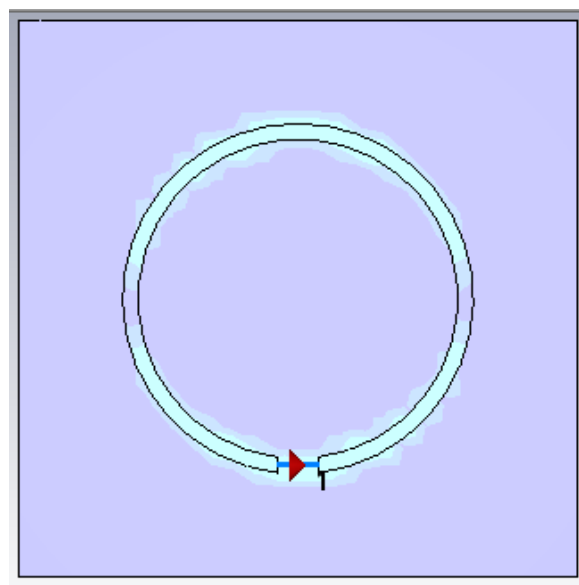

(a) Metamaterial antenna without metamaterial

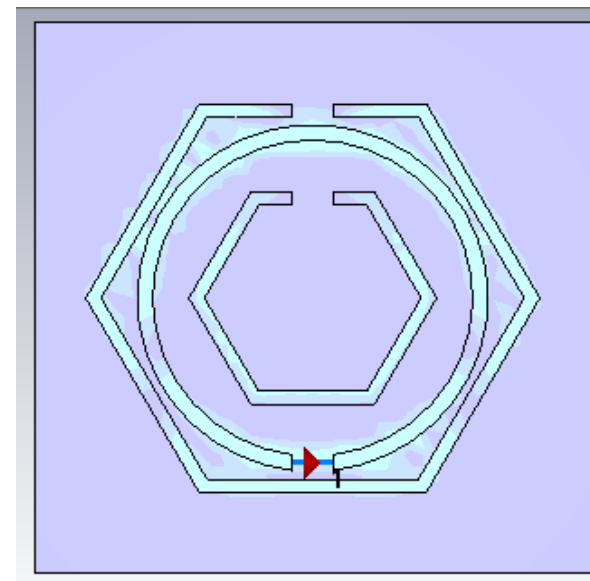

(b) Metamaterial antenna

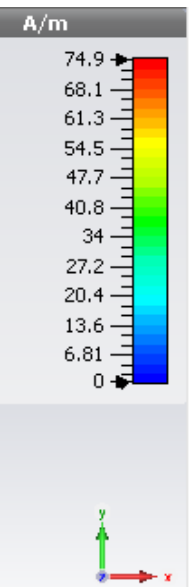

Figure 7. Magnetic field distribution

\section{CONCLUSION}

A novel contribution has been made to enhance and miniaturise the UHF-functioning RFID antenna utilizing the hexagonal split ring resonator. We can demonstrate the effectiveness of our method from the best simulation results. Accordingly, we can obtain a very high frequency antenna with very little size, utilizing this technique.

\section{ACKNOWLEDGMENT}

The research being reported in this publication was supported by the Algerian Directorate General for Scientific Research and Technological Development (DGRSDT).

\section{REFERENCES}

[1] Veselago, V.G. (1968). The electrodynamics of substances with simultaneously negative values of \$lepsilon\$ and $\mu$. Soviet Physics Uspekhi, 10(4): 508. https://doi.org/10.1070/PU1968v010n04ABEH003699

[2] Pendry, J.B., Holden, A.J., Stewart, W.J., Youngs, I. (1996). Extremely low frequency plasmons in metallic mesostructures. Physical Review Letters, 76: 4773.
http://dx.doi.org/10.1103/PhysRevLett.76.4773

[3] Shelby, R.A., Smith, D.R., Schultz, S. (2001). Experimental verification of a negative index of $\begin{array}{lll}\text { refraction. } & \text { Science, } & \text { 292(5514): }\end{array}$ http://dx.doi.org/10.1126/science. 1058847

[4] Sanada, A., Caloz, C., Itoh, T. (2004). Characteristics of the composite right/left-handed transmission lines. IEEE Microwave and Wireless Components Letters, 14(2): 6870. http://dx.doi.org/10.1109/LMWC.2003.822563

[5] Ferchichi, A., Gharsallah, A. (2013). A circuit model to an encoche coplanar antenna for a radio frequency identification TAG. International Journal of Electrical and Computer Engineering (IJECE), 3(3): 386-391. https://dx.doi.org/10.11591/ijece.v3i3.2579

[6] Naoui, S., Latrach, L., Gharsallah, A. (2014). Nested metamaterials antenna for RFID traceability. Microwave and Optical Technology Letters, 56(7): 1622-1626. https://doi.org/10.1002/mop.28393

[7] Ennajih, A., Zbitou, J., Latrach, M., Errkik, A., Mandry, R. (2017). A new dual band printed metamaterial antenna for RFID reader applications. International Journal of Electrical and Computer Engineering, 7(6): 3507-3514. http://dx.doi.org/10.11591/ijece.v7i6.pp3507-3514

[8] Jung, Y.K., Lee, B. (2011). Dual-band circularly polarized microstrip RFID reader antenna using metamaterial branch-line coupler. IEEE Transactions on 
Antennas and Propagation, 60(2): 786-791. http://dx.doi.org/10.1109/TAP.2011.2167943

[9] Naoui, S., Latrach, L., Gharsallah, A. (2014). Metamaterials dipole antenna by using split ring resonators for RFID technology. Microwave and Optical Technology Letters, 56(12): 2899-2903. https://doi.org/10.1002/mop.28731

[10] Naoui, S., Latrach, L., Gharsallah, A. (2015).
Metamaterials microstrip patch antenna for wireless communication RFID technology. Microwave and Optical Technology Letters, 57(5): 1060-1066. https://doi.org/10.1002/mop.29016

[11] Wang, Z., Dong, Y., Itoh, T. (2021). Metamaterial-based, miniaturised circularly polarised antennas for RFID application. IET Microwaves, Antennas \& Propagation, 15(6): 547-559. https://doi.org/10.1049/mia2.12064 